\title{
FENOMENOLOGÍA
}

\section{EL SENTIDO DE CUIDAR RELATO DE UNA EXPERIENCIA HOSPITALARIA}

\author{
José Manuel Tordera Alba \\ Diplomado en Enfermería
}

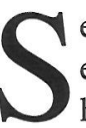
e habla mucho de práctica enfermera basada en la evidencia, de ser objetivo, pero no se habla de algo igualmente importante en Enfermería como es de los actos de amor.

\section{HECHOS}

El martes 8/4/03, a las 13,30h. ingresé en urgencias del hospital de Vellvitge de Barcelona (en nivel 2, creo que le llaman asî) por presentar melenas que yo había comprobado en casa minutos antes.

Hacia las 15 h. se me practicó un hematocrito que dio un valor de 26 .

Hacia las $20 \mathrm{~h}$, más o menos me fue practicada una endoscopia (sin sedación); el endoscopista me indicó que tenía una úlcera duodenal sangrante bastante grande.

\section{RELATO Y REFLEXIÓN}

La endoscopia duró poco, pero a mi se me hizo eterna (como se demostró minutos después, mi hematocrito en el momento de la prueba debía rondar el valor de 20 con una hemoglobina de 6 , por lo que en aquel momento yo no estaba muy sobrado de fuerzas). Aquel mecanismo dentro de mí me estaba provocando una náusea continua, parecía que el estómago se me iba a salir por la boca (el tubo no entró hasta el segundo intento, quizá por eso le llaman EN-DOS-COPIAS); yo no ayudaba demasiado, no tenía fuerzas para obedecer ninguna instrucción, no tenía dolor, pero padecía una sensación de ahogo inminente y me movía hacia todos los lados, jaquello parecía un invento del Marqués de Sade!

En medio de aquel padecimiento, donde yo me encontraba objetivamente rodeado de personal téc- nicamente competente (sé que lo son) yo me sentía subjetivamente SOLO, PERDIDO Y ABANDONADO, pero... ¡sí, hay un pero, bendito pero!, una persona que estaba detrás de mí me tomó de la mano, yo la apreté fuertemente, eso fue la tabla de mi salvación emocional; aquello fue un acto $\mathrm{DE}$ CUIDAR, de apoyo, de dolor compartido, de acompañamiento humano, de amor en definitiva. Era la mano de Rafi, una auxiliar de clínica del quirófano de urgencia.

El saber médico y el saber enfermero en términos de lo técnicamente posible, objetivo y evidenciable es importantísimo; pero si la persona que "sabe" no tiene la tendencia además, de 'salir de sí mismo' para entrar en el mundo del otro, compartir, comprender, acompañar, no existe ningún saber en absoluto.

El verdadero progreso humano no está en la ciencia sino en la afectividad, progreso humano que se demuestra en la pequeñas cosas que a la vez son las más potentes, como el acompañamiento verdadero en el sufrimiento, donde las palabras de "tranquilízate, tranquilízate" no valen; valen las acciones, que son hechos que tienen sentido, significado.

Para mí significó mucho que me cogieran de la mano, me ayudó a relajarme, era justo lo que necesitaba, y alguien se dio cuenta; esa acción es genuinamente cuidado enfermero. A las personas que trabajamos en Enfermería nos pagan por una serie de tareas que hemos de realizar, pero ser enfermera o enfermero no es únicamente eso. Opino que el trabajo realmente enfermero no está pagado con nada, como no se puede pagar a una madre por querer a sus hijos. Si el trabajo enfermero es únicamente dar de comer y beber, vestir y desvestir 
etc., cualquier día seremos sustituidos por una máquina; la tensión arterial la toma ya una máquina sin intervención del oído humano. Podemos imaginar un futuro en el que el paciente introduzca un brazo desnudo en una máquina portátil y sin ningún tipo de dolor lo saque a los pocos segundos con una vía pinchada, podemos imaginar un futuro en el que la comida la demande directamente el paciente a un 'aparato' instalado en la pared de su habitación diciendo: "sopa de fideo fino a $40^{\circ}$ " y ésta aparezca como en las películas de ciencia ficción y posteriormente un robot le vaya dando cucharaditas si el paciente no puede o no sabe, etc. Pero lo que no puede ofrecer una máquina es el acercamiento humano al sufrimiento de los otros, la comprensión, la intersubjetividad, el afecto, el tocar al paciente transmitiendo interés, el deseo de acompañar en el proceso salud-enfermedad etc., por mucha carga de trabajo que tengamos, siempre hay un segundo para ofrecer una sonrisa, un guiño, una broma a un niño ingresado, ofrecer un punto de referencia a quien está en una cámara estéril mostrándole tu cara por unos segundos apartando la mascarilla de tu cara, un esfuerzo por no decir nunca (cosa que todos hacemos por buena fe) ¡anímate! a quien no se puede animar, un tomar de la mano para acompañar en un momento ingrato. Esas acciones dan sentido al cuidado enfermero, no la técnica; la técnica no es un fin en sí mismo, sólo es un medio para un fin, y el sentido de cuidar no es único sino múltiple, no es fijo sino variable, no es general sino particular, no es independiente del contexto sino dependiente, en fin, a eso llamo yo actos de amor.

\section{HECHOS II}

Pocos minutos después de acabada la endoscopia ya me encontraba en el box y sufrí una crisis hipovolémica con desvanecimiento, midriasis, vómito, relajación de esfínteres y convulsión (TA: $60 / 30$ ). Puedo contarlo gracias a la rápida actuación técnica de médicos y enfermeras y a un Ringer a chorro y dos bolsas de sangre "a la desesperada" en palabras de la doctora que informó a mi mujer (sin tiempo para pruebas cruzadas).

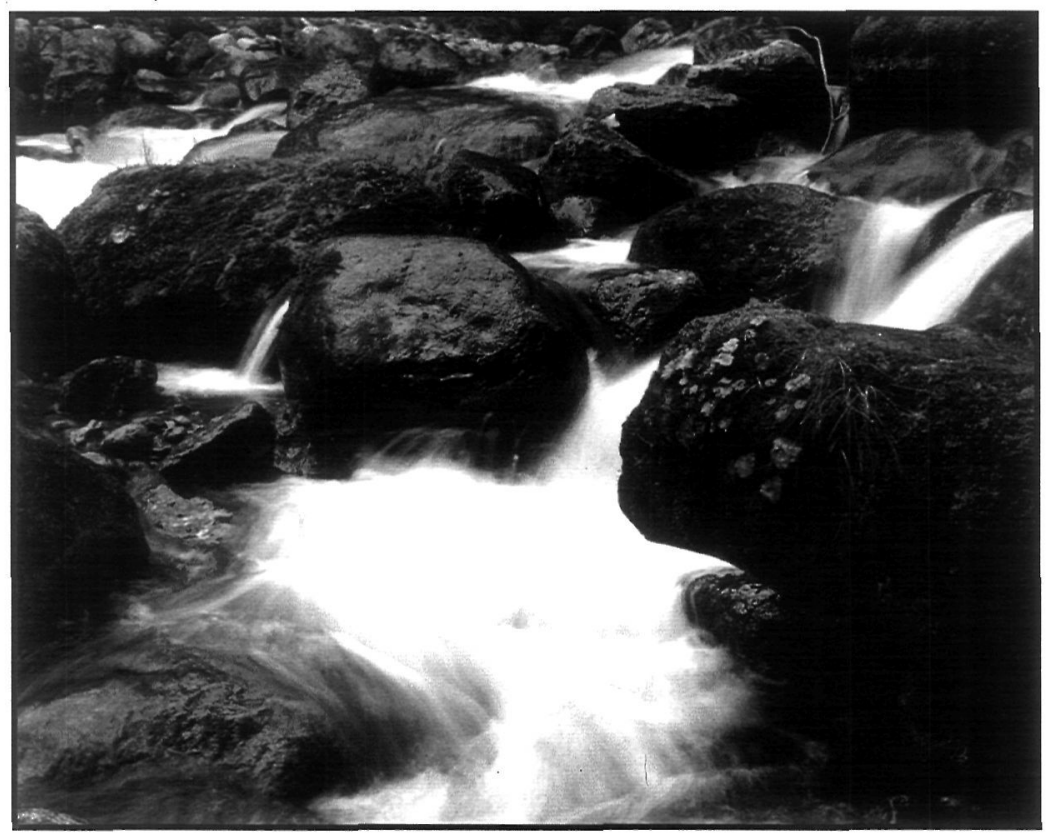

